\title{
Health effects of a subway environment in
}

\section{healthy volunteers}

\author{
A. Klepczyńska Nyström*, M. Svartengren*, J. Grunewald\#, C. Pousette ${ }^{\#}$, I. Rödin*, \\ A. Lundin*, C.M. Sköld ${ }^{\#}$, A. Eklund ${ }^{\#}$ and B-M. Larsson*
}

\begin{abstract}
Environmental particle exposure, often estimated as the particulate mass of particles with a diameter $<10 \mu \mathrm{m},<2.5 \mu \mathrm{m}$ or $<1 \mu \mathrm{m}$ (PM10, PM2.5 or PM1), is known to have a negative impact on the health of the population. Little is known about how the size and origin of particles influence the effects. We have previously shown that exposure to a road tunnel environment causes a cellular inflammatory response in the airways of healthy individuals. In the present study, our aim was to investigate potential airway health effects from exposure to a subway environment.
\end{abstract}

20 healthy volunteers were exposed to a subway and a control environment for $2 \mathrm{~h}$, followed by measurements of lung function and the inflammatory response in the lower airways (bronchoscopy) and in the peripheral blood.

No cellular response was found in the airways after exposure to the subway environment. In the blood, we found a statistically significant increase in fibrinogen and regulatory T-cells expressing CD4/CD25/FOXP3.

Subway and road tunnel environments have similar levels of PM10 and PM2.5, whilst the concentrations of ultrafine particles, nitrogen monoxide and dioxide are lower in the subway. Although no cellular response was detected, the findings indicate a biological response to the subway environment. Our studies show that using gravimetric estimates of ambient particulate air pollution alone may have clear limitations in health-risk assessment.

KEYWORDS: Air pollution, bronchoscopy, inflammation, inhalation exposure, particle size

P articulate air pollution is considered to be a potential health problem. Combustion exhaust from motor traffic is a major contributor to ambient air pollution and is probably one of the main causes of cardiovascular morbidity and mortality observed in a number of epidemiological studies [1, 2]. The mechanisms behind these effects are still not fully understood. One suggested hypothesis is that inflammatory events induced by exposure to particles can influence the coagulation system. Particles could also have a direct impact on the heart by causing changes in heart rate variability. A case crossover study indicated that even a moderate increase in air pollution has effects on ventricular arrhythmias in patients with an implantable cardioverter defibrillator [3].

Particulate air pollution is usually monitored by gravimetric measurements of the particulate mass of particles with a diameter $<1 \mu \mathrm{m},<2.5 \mu \mathrm{m}$ or $<10 \mu \mathrm{m}$ (PM1, PM2.5 and PM10). Measurements of ultrafine (UF) particles, defined as particles with a diameter $<100 \mathrm{~nm}$, are rarely monitored. Because of their low mass, measurement of number concentration is more relevant for UF particles. Motor exhaust is a major source of UF particles in the urban environment and has generally increased in the city environment. Several studies have shown that UF particles are more potent in inducing an inflammatory response [4-6]. In an in vivo study in rats, urban PM10 particles and UF carbon black particles were instilled in the lungs, and bronchoalveolar lavage (BAL) was performed after $6 \mathrm{~h}$. Both the PM10 and UF particles induced an inflammatory response, but the latter gave a greater influx of neutrophils [7].

One way of limiting air pollution related to motor exhaust is by encouraging the use of public transportation. Particle exposure measured as PM10 has, however, been found to be high in the subway environment. In Stockholm (Sweden), the PM levels in the subway are 5-10 times higher than at street level in the inner city area [8] and comparable to those found in the road tunnel [9]. This is also the case in several other cities such as London (UK) [10, 11], Rome (Italy) [12], New York (NY, USA) [13] and Seoul (Republic of Korea) [14]. In the subway, airborne particles are usually $>1 \mu \mathrm{m}$
AFFILIATIONS

*Dept of Public Health Sciences,

Division of Occupational and Environmental Medicine, and

${ }^{\#}$ Dept of Medicine, Division of Respiratory Medicine, Karolinska Institutet, Stockholm, Sweden.

\section{CORRESPONDENCE}

A. Klepczyńska Nyström Dept of Public Health Sciences, Division of Occupational and

Environmental Medicine

Karolinska Institutet

Norrbacka

4th floor

SE-17176 Stockholm

Sweden

E-mail:

anna.klepczynska-nystrom@ki.se

Received:

June 262009

Accepted after revision: Dec 072009

First published online:

Dec 232009

Online ISSN 1399-3003 
and originate mainly from the wearing of tracks and wheels, leading to a high content of iron. Compared to the street environment, the number concentration of UF particles is, however, of a much lower magnitude in the subway environment.

Assessment of personal PM10 exposure has previously been performed on personnel working in the Stockholm subway. Exposure levels for subway drivers were compared with platform workers. The latter group was exposed to levels of particles four times higher than the train drivers' [15]. This suggests that exposure in the subway environment could also have an impact on citizens using the subway. Another study showed that the inflammatory response, measured as blood plasma concentrations of plasminogen activator inhibitor (PAI)-1, interleukin (IL)-6 and fibrinogen, had a tendency to be higher for subway platform workers than for train drivers and subway ticket sellers. Measurements were performed on nonsmoking healthy workers after two non-working days and after two working days [16].

In an earlier in vivo study performed in a road tunnel, we demonstrated that particles derived from motor traffic induce inflammatory reactions in the lower airways of healthy individuals, such as increased concentration of inflammatory cells in BAL fluid (BALF) [9].

The aim of the present study was to assess whether or not exposure in the subway environment would induce acute inflammatory effects in the lower airways in healthy individuals, as was observed in the road tunnel study. The two environments have similar PM2.5 and PM10 mass concentration levels but differ in UF number concentration and composition. The comparison of the acute biological response derived from inhaled particles in relation to size and composition could give guidance as to the kind of particles that impose the most potent risk factor to human health.

The study design was chosen to facilitate direct comparison with results obtained in the previously mentioned road tunnel exposure study [9]. Cellular response and inflammatory mediators were explored in blood and by performing BAL, and the effects on lung function were measured by spirometry. Blood samples were taken to investigate the effect on the coagulation system (fibrinogen and PAI-1).

\section{METHODS}

\section{Volunteers}

20 healthy, nonsmoking volunteers (seven females) with a mean age of 27 (range 18-46) yrs participated in the study. All volunteers underwent a routine physical examination (table 1). Chest radiography and lung function tests were normal. None of the volunteers had any symptoms in the airways. In vitro screening for the presence of specific immunoglobin (Ig)E antibodies against common inhaled allergens (Phadiatop; Pharmacia-Upjohn, Uppsala, Sweden) showed that $90 \%$ of the volunteers had no IgE antibodies.

Airway infections were not allowed within 6 weeks before exposures. All participants gave their informed consent to participate in the study, which was approved by the local ethical committee at the Karolinska Institutet (Stockholm, Sweden).

\section{Study design}

The study was carried out between mid-October 2006 and mid-March 2007 in Stockholm. The randomised crossover experimental design involved exposure to both a subway environment and an office environment (control). The volunteers served as their own controls. As shown in figure 1, the volunteers were randomised to start with exposure in either the subway or the control environment. The second exposure followed an interval of $\geqslant 3$ weeks. $14 \mathrm{~h}$ after each exposure, bronchoscopies and blood sampling were performed.

During participation in the study the volunteers were told to perform ordinary daily activities. However, no transportation using the subway system was allowed during the whole study period. The volunteers were also encouraged to avoid heavy physical activities during the days of measurements and to avoid staying in areas with heavy air pollution.

The study design was chosen to enable comparison with a previous exposure study performed in a road tunnel where inflammatory effects were seen [9]. Our study included a similar study population in terms of age and sex, the same exposure time and sampling time, as well as the same methods of clinical and exposure measurements.

\section{Location of exposures}

Subway exposures were performed during afternoon rush hour (16:00-18:00 h) at the platform of a subway station (Odenplan) in the central part of Stockholm. The exposure took place in a room located a few metres below the subway platform level with the corresponding air quality to the platform level (data not shown). The room had two doors on opposite sides which were open to the adjacent platform during the exposure session. Control exposures were performed during the corresponding hours in an office environment.

During the exposure sessions the volunteers alternated 15-min intervals of moderate exercise on a bicycle ergometer with 15 min of rest. The ergometer resistance was adjusted to achieve an individual minute ventilation rate of $20 \mathrm{~L} \cdot \mathrm{min}^{-1} \cdot \mathrm{m}^{-2}$ body surface area. Self-stated symptoms were recorded during exposure sessions (see below for details).

\section{Environmental exposure measurements}

Exposure levels were monitored during each exposure session. Sampling of PM2.5 and PM10 particles (with an upper 50\% cutoff aerodynamic diameter of 2.5 and $10 \mu \mathrm{m}$, respectively) in the subway environment was performed using Harvard impactors (Air Diagnostics and Engineering Inc, Harrison, ME, USA), equipped with Teflon filters (Air Diagnostics and Engineering Inc), and with a pore size of $2 \mu \mathrm{m}$ and at a flow rate of $\sim 10 \mathrm{~L} \cdot \mathrm{min}^{-1}$. The filters were weighed after $24 \mathrm{~h}$ of conditioning using a Mettler Toledo MT5 scale (Mettler, Greisensee, Switzerland) but were also analysed for a range of metals using inductively coupled plasma mass spectrometry (ICP-MS).

The number concentration of airborne UF particles with an aerodynamic diameter of 14-100 nm was determined using a scanning mobility particle sizer (SMPS) system consisting of Electrostatic Classifier model 3081 (TSI, Shoreview, MN, USA) in combination with Condensation Particle Counter (CPC) model 3010 (TSI). Nitrogen oxides ( $\mathrm{NO}$ and $\mathrm{NO}_{2}$ ) levels were 


\begin{tabular}{|c|c|c|c|c|c|c|}
\hline 1 & 26 & - & $M$ & 87 & 104 & 105 \\
\hline 2 & 28 & - & $F$ & 125 & 120 & 104 \\
\hline 3 & 27 & - & $\mathrm{F}$ & 135 & 121 & 120 \\
\hline 5 & 22 & - & M & 106 & 112 & 88 \\
\hline 6 & 25 & - & M & 105 & 108 & 106 \\
\hline 7 & 42 & - & M & 110 & 115 & 111 \\
\hline 8 & 31 & - & $\mathrm{F}$ & 100 & 91 & 88 \\
\hline 9 & 25 & - & $M$ & 88 & 87 & 86 \\
\hline 10 & 25 & - & $\mathrm{F}$ & 110 & 104 & 105 \\
\hline 15 & 25 & - & $M$ & 101 & 112 & 115 \\
\hline 16 & 26 & - & M & 117 & 123 & 116 \\
\hline 17 & 29 & - & $\mathrm{F}$ & 105 & 101 & 91 \\
\hline 18 & 26 & + & M & 115 & 129 & 115 \\
\hline 19 & 27 & - & M & 120 & 124 & 114 \\
\hline 20 & 46 (max) & - & M & 118 & 116 & 120 \\
\hline Summary & Mean 27 & $2+$ & $7 \mathrm{~F}$ & Mean \pm SD $112 \pm 14$ & Mean \pm SD $114 \pm 13$ & Mean \pm SD $109 \pm 12$ \\
\hline
\end{tabular}

VC: vital capacity; \% pred: \% predicted; FVC: forced vital capacity; FEV1: forced expiratory volume in $1 \mathrm{~s}$; M: male; F: female.

monitored using a chemiluminescent instrument (AC 31M; Environnement, Poissy, France).

During the control exposures, portable logging instruments were used. To enable comparison of particle exposure levels, these instruments were also used during exposure sessions in the subway environment. The two portable logging instruments were DataRAM pDR1000 (Thermo Fischer Scientific, Waltham, MA, USA), which measures the mass of particles between 0.1 and $10 \mu \mathrm{m}$ in diameter (PM0.1-10), and P-Trak (TSI), a particle counter that estimates the number of particles between 20 and 1,000 $\mathrm{nm}$ in diameter.

\section{Self-reported symptoms}

During the exposure sessions, self-reported symptoms of irritation of the eyes, upper and lower airways and a disturbing smell were recorded before and every $30 \mathrm{~min}$ throughout the exposure. The intensity was graded from 0 to 10 , where 0 corresponded with no symptoms and 10 with severe symptoms, according to a modified visual analogue scale (VAS).

\section{Lung function tests}

Lung volume was measured with a spirometer (Jaeger $^{\mathrm{TM}}$ Masterscope ${ }^{\mathrm{TM}}$; CareFusion $\mathrm{GmbH}$, Hoechburg, Germany) and included vital capacity (VC), forced vital capacity (FVC) and forced expiratory volume in $1 \mathrm{~s}$ (FEV1). We also measured exhaled NO levels (Niox Mino, Aerocrine AB, Solna, Sweden). Measurements were performed immediately before bronchoscopies.
Measurements of peak expiratory flow (PEF) were performed with a portable lung health monitor (PIKO-1; nSpireHealth, Longmont, $\mathrm{CO}$, USA) just before the exposure session, after $1 \mathrm{~h}$ and immediately after the 2 -h session. Each volunteer was instructed to repeat measurements at around 20:00 h, 22:00 h, 06:00-07:00 h as well at the clinic at 07:30-08:00 $\mathrm{h}$ the following morning.

\section{Peripheral blood}

Peripheral blood was sampled in connection with bronchoscopy. Cell differential counts were performed using an autoanalyser (Siemens Healthcare Diagnostics, Deerfield, IL, USA). Plasma fibrinogen, which is involved in the coagulation system, was analysed by a kinetic fibrinogen assay. PAI-1 was analysed using an enzyme-linked immunosorbent assay (ELISA) (Chromolize PAI-1, Biopool; Trinity Biotech, Bray, Ireland). Blood was also used for immunostaining and flow cytometric analysis.

\section{Bronchoscopy, BAL and bronchial washing}

BAL was performed by inserting a flexible fibreoptic bronchoscope (Olympus; Olympus Optical Co Ltd, Tokyo, Japan) under local anaesthesia, as described in detail by EKLUND and BLASCHKE [17]. $250 \mathrm{~mL}$ sterile PBS was instilled into the middle lobe in five aliquots of $50 \mathrm{~mL}$ each. After each instillation, the fluid was gently aspirated and collected and kept on ice.

The BALF was filtered through a single layer of Dacron net (Millipore, Cork, Ireland) and centrifuged at $400 \times g$ for $10 \mathrm{~min}$ at $4{ }^{\circ} \mathrm{C}$. The pellet was resolved in RPMI 1640 medium (SigmaAldrich, Saint Louis, MO, USA). Cells were counted and total 


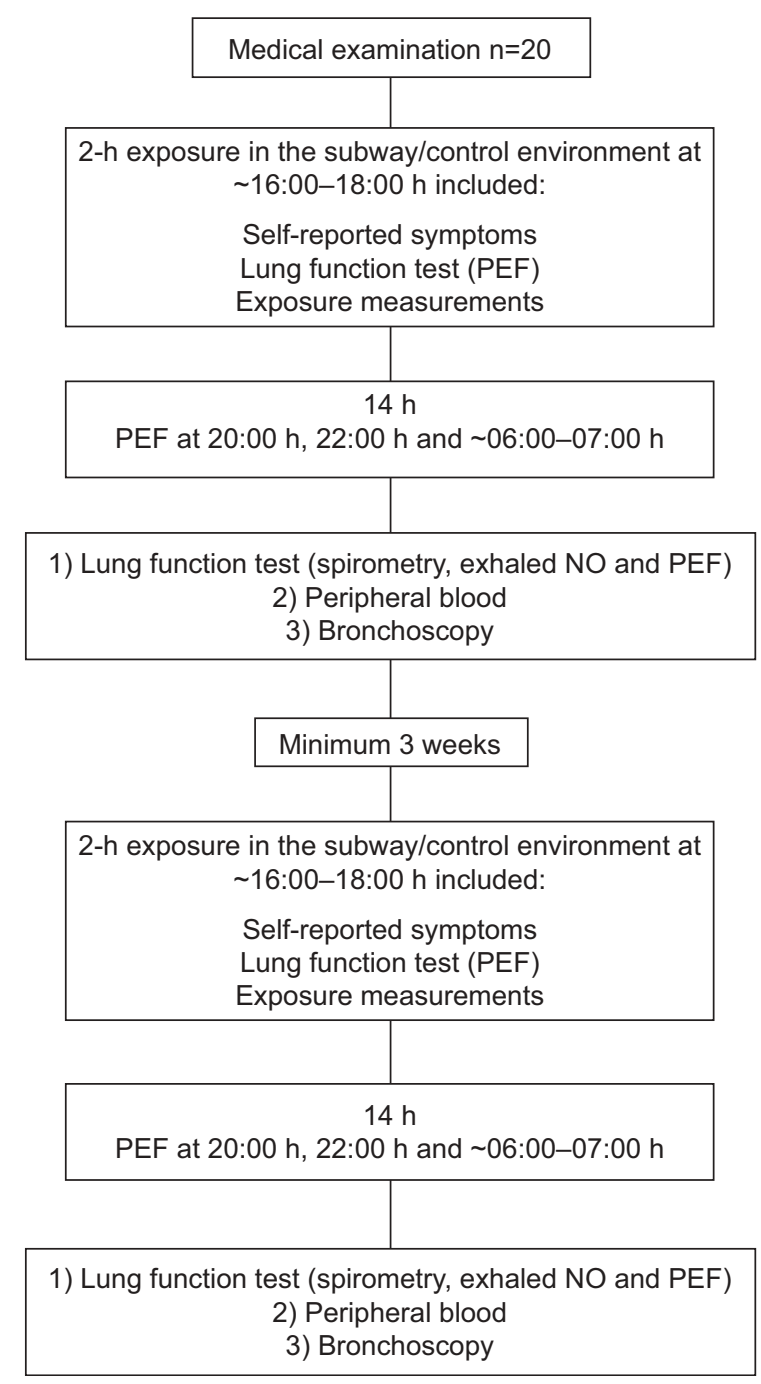

FIGURE 1. Study design: randomised crossover experimental design with exposure to a subway environment and an office environment (control). PEF: peak expiratory flow; NO: nitric oxide.

cell viability (mean 94.4\%) was determined by trypan blue exclusion using a Bürker chamber. The BALF cell pellet was also used for immunostaining and flow cytometric analysis (see below).

The supernatant was analysed for inflammatory cytokines IL1B, IL-6, IL-8, IL-10, IL-12p70 and tumour necrosis factor (TNF)- $\alpha$. Cytokine analyses were performed by flow cytometry (FACSCalibur; Becton Dickinson, Franklin Lakes, NJ, USA) using the cytometric bead array technique (Becton Dickinson).

Bronchial washing was performed in a segmental bronchus in the upper lobe by instilling $2 \times 10 \mathrm{~mL}$ sterile PBS. Each instillation was followed by dental aspiration of fluid.

\section{Immunostaining and flow cytometric analysis}

The TBNK 6-Colour Multitest was used to determine lymphocyte subsets in BALF and erythrocyte-lysed human peripheral blood. TBNK consists of a combinations of fluorochrome conjugated monoclonal antibodies for T-cells, B-cells and natural killer (NK) cells. We also used a set of monoclonal antibodies specific for markers of T-cell activity and T-cell regulatory functions.

For each analysis, $1 \times 10^{6}$ BALF cells were incubated with antibodies for $30 \mathrm{~min}$ in the dark and kept on ice at $4{ }^{\circ} \mathrm{C}$; blood was kept at room temperature. Blood samples were lysed with lysing solution and washed twice with cell wash (BD Biosciences, San Jose, CA, USA). All samples were analysed by a flow cytometer using an eight-colour FACSCanto II (Becton Dickinson). $\sim 2.5 \times 10^{5}$ cells were collected from each sample. Lymphocytes were gated by forward and side scatters. For the TBNK multitest, a gate was set for CD45 (white blood cells). For the T-cell activation and T-regulatory panels, a gate was set for CD3 cells (T-cells). Isotype-matched negative control antibodies always stained $<1 \%$. The antibody combinations used in BALF and blood are shown in the Appendix (table 3). All monoclonal antibodies were from BD Biosciences, with the exception of FOXP3 which was obtained from eBiosciences (San Jose, CA, USA).

\section{Statistical analysis}

Statistical analysis was carried out with SPSS version 15.0 (SPSS Inc, Chicago, IL, USA) on a Windows-based PC platform. Individual changes in different parameters for subway and control exposure were analysed using Wilcoxon's non-parametric rank sum tests. A paired t-test was performed for lung function data and exposure measurements. p-values of $<0.05$ were regarded as significant.

\section{RESULTS}

\section{Environmental exposure measurements}

During a total of 10 subway exposures, the mean \pm SD levels of PM2.5 and PM10 were $77 \pm 10$ and $242 \pm 40 \mu \mathrm{g} \cdot \mathrm{m}^{-3}$, respectively. The number concentration of ambient airborne particles with an aerodynamic diameter $<100 \mathrm{~nm}$ was $8,283 \pm 1,716$ particles $\cdot \mathrm{mL}^{-1}$. The mean level of nitrogen monoxide was $58 \pm 12 \mu \mathrm{g} \cdot \mathrm{m}^{-3}$ while for nitrogen dioxide it was $24 \pm 3 \mu \mathrm{g} \cdot \mathrm{m}^{-3}$. A comparison with exposure measurements in the road tunnel is shown in table 2 .

All but four metals (iron, barium, copper and manganese) were below the detection limits (ICP-MS). The mean \pm SD content of metals in the PM10 fraction was $58.6 \pm 21.0 \%$ iron, $1.0 \pm 0.4 \%$

\begin{tabular}{|c|c|c|}
\hline & Subway & Road tunnel \\
\hline $\begin{array}{l}\text { Ultrafine particles number } \\
\text { concentration } \cdot \mathrm{mL}^{-1}\end{array}$ & 8266 & 110000 \\
\hline PM2.5 mass concentration $\mu \mathrm{g} \cdot \mathrm{m}^{-3}$ & 76 & 64 \\
\hline PM10 mass concentration $\mu \mathrm{g} \cdot \mathrm{m}^{-3}$ & 237 & 176 \\
\hline $\mathrm{NO} \mu \mathrm{g} \cdot \mathrm{m}^{-3}$ & 59 & 874 \\
\hline $\mathrm{NO}_{2} \mu \mathrm{g} \cdot \mathrm{m}^{-3}$ & 24 & 230 \\
\hline \multicolumn{3}{|c|}{$\begin{array}{l}\text { Median values for environmental exposure measurements in the subway in } \\
\text { comparison with levels in a previously investigated road tunnel in the same city } \\
\text { and during the same seasons [9]. PM2.5 and PM10: particulate mass of particles } \\
\text { with a diameter }<2.5 \text { and }<10 \mu \mathrm{m} \text {, respectively; NO: nitrogen monoxide; } \mathrm{NO}_{2} \text { : } \\
\text { nitrogen dioxide. }\end{array}$} \\
\hline
\end{tabular}


barium, $0.8 \pm 0.4 \%$ of copper and $0.5 \pm 0.2 \%$ manganese. The content of metals in the PM2.5 fraction was to a large extent below the detection limit. No analysis of endotoxins was performed, but an in vitro study showed that subway particles contained endotoxin below the detection limit $\left(0.01 \mathrm{pg} \cdot \mathrm{mL}^{-1}\right)$ [18].

For the control exposure, the mean \pm SD level of PM0.1-PM10 (using DataRAM) was $16 \pm 4 \mu \mathrm{g} \cdot \mathrm{m}^{-3}$ while the number of particles between 20 and 1,000 $\mathrm{nm}$ in diameter (using P-Trak) was $1,007 \pm 660$ particles $\cdot \mathrm{mL}^{-1}$. The corresponding levels in the subway environment were $162 \pm 25 \mu \mathrm{g} \cdot \mathrm{m}^{-3}$ and $10,549 \pm 1,453$ particles $\cdot \mathrm{mL}^{-1}$, respectively.

\section{Symptoms}

In comparison with the control exposures, self-reported symptoms of irritation from the lower airways were significantly higher during exposure to the subway environment. Experience of a disturbing smell was also higher. Irritative symptoms from the nose had a tendency to be higher during exposure to the subway environment $(p=0.054)$, while the irritative symptoms from the eyes were not affected.

\section{Lung function tests}

No significant changes between subway and control exposures were observed in VC, FVC, FEV1, exhaled $\mathrm{NO}$ or PEF. Additional data are shown in the Appendix (table 4).

\section{Peripheral blood}

The total number of cells, cell concentrations or distribution of different cell populations in blood did not differ between control and subway exposures. Fibrinogen levels in the peripheral blood increased from $2.2 \mathrm{~g} \cdot \mathrm{L}^{-1}$ (interquartile range 2.00-2.38) after control exposure to $2.3 \mathrm{~g} \cdot \mathrm{L}^{-1}(2.21-2.58)$ after the subway exposure $(p=0.026)$. Levels of PAI- 1 were often below the detection limit of $<5$ kilounits $\cdot \mathrm{L}^{-1}$ (14 volunteers after the subway exposure, 13 after the control). In order to perform statistical analysis, these cases were assigned a value of 3. No significant changes were found in the levels of PAI-1 (see Appendix, table 4).

\section{BALF and bronchial wash fluid}

No significant changes were seen in BALF or bronchial wash fluid between subway and control exposures with regard to recovery, cell viability, total number of cells, cell concentration or distribution of different cell populations, nor were any significant changes seen in cytokine expression in the BALF. Additional data are shown in the Appendix (table 4).

\section{Immunostaining and flow cytometric analysis}

The T-cell (CD4)/T-cytotoxic-suppressor (CD8) ratio in BALF and blood was similar following control and subway exposures. In BALF, the median ratio was 2.2 (control) versus 2.0 (subway), and in blood it was 2.0 (control) versus 2.2 (subway). NK T-cells defined as lymphocyte gated cells simultaneoulsly positive for CD3, CD56 and CD16 (CD3 ${ }^{\text {pos }} \mathrm{CD} 56^{\text {pos }} \mathrm{CD} 16^{\mathrm{pos}}$ ) remained unchanged. Subway exposure had a tendency to increase NK-cells $\left(\mathrm{CD} 3^{\text {neg }} \mathrm{CD} 56^{\text {pos }} \mathrm{CD} 16^{\mathrm{pos}}\right)$ in blood $(\mathrm{p}<0.09)$ but not in BALF.

In blood the percentage frequency of CD4 cells expressing the T-cell activation marker CD69 (CD4 $\left.{ }^{\text {pos }} / C D 69^{\text {pos }}\right)$ increased significantly after exposure in the subway $(\mathrm{p}<0.003)$. The median value changed from 2.9\% (interquartile range 2.3$3.3 \%$ ) after control exposure to $3.5 \%(3.0-4.0 \%)$ after subway exposure. The same applied to $\mathrm{CD} 4^{\text {pos }} /$ human leukocyte antigen (HLA)-DR ${ }^{\text {pos }}$, which increased from 6.5\% (5.8-8.0\%) to $7.0 \%(6.3-8.3 \%)(p<0.03)$. A tendency for percentage increase of $\mathrm{CD} 4^{\text {pos }} / \mathrm{CD} 25^{\text {pos }}$ cells $(\mathrm{p}<0.07)$ was observed. The relative number of CD8 cells expressing the T-cell activation marker CD69 increased significantly after exposure in the subway $(\mathrm{p}<0.01)$, from $2.9(2.2-3.7)$ after control to $3.8(2.5-5.5)$ after subway exposure. In BALF, no such differences were seen.

The percentage frequency of CD4 cells expressing the T-regulatory marker FOXP3 or CD25 bright $/ F O X P 3$ increased significantly in blood after subway exposure $(p<0.03$ for both, see fig. 2$)$. No such difference was seen in BALF after subway exposure.
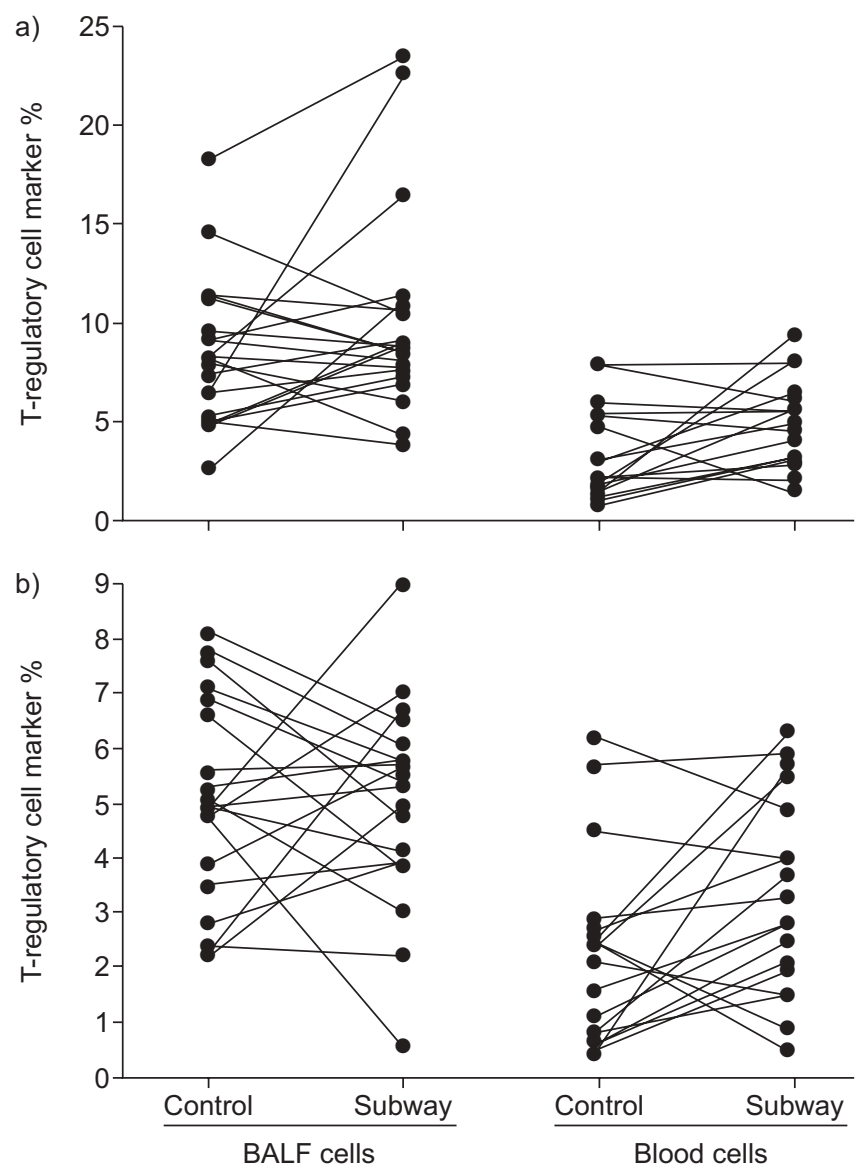

FIGURE 2. Frequency of $\mathrm{CD} 4$ cells expressing the T-regulatory marker a) FOXP3 (CD4 $4^{\text {pos }} /$ FOXP3) and b) CD25 ${ }^{\text {bright }}$ and FOXP3 (CD4 $4^{\text {pos }}$ CD25 bright/ FOXP3) in bronchoalveolar lavage fluid (BALF) and peripheral blood after control and subway exposure. a) In blood, the percentage of CD4 $4^{\text {pos }} / F O X P 3$ cells increased from 2.1 (interquartile range 1.5-5.4) after control exposure to 4.3 (2.55.9) after subway exposure $(p=0.03)$. In BALF, the relative number increased from 8.1 (5.2-9.4) to 8.8 (7.5-10.9), which was non-significant. b) In blood the percentage of $\mathrm{CD} 4^{\text {pos }} \mathrm{CD} 25^{\text {bright }} / \mathrm{FOXP3}$ cells increased from 2.1 (0.8-2.7) after control exposure to $2.8(1.7-4.5)$ after subway exposure $(p=0.03)$. In BALF, the relative number increased from $4.9(3.7-6.8)$ to $5.4(3.9-6.0)$ and was nonsignificant. 


\section{DISCUSSION}

We have found that a 2-h exposure in the subway environment leads to significantly increased expression of markers for regulatory T-cells as well as elevated levels of fibrinogen in peripheral blood in healthy volunteers. The subway environment also appeared to induce irritative symptoms in the lower airways.

In our earlier in vivo study, we showed that exposure to particles derived from city traffic increased the amount of inflammatory cells in the BALF of healthy individuals [9]. Since the exposure levels of gravimetric parameters such as PM2.5 and PM10 are the same when comparing the two studies, one would expect that the inflammatory effects observed in the road tunnel study would also be seen after exposure in the subway environment. However, no signs of a cellular inflammatory response in the lower airways assessed by bronchoscopy were found after exposure to the subway environment, regardless of whether the cells were retrieved from peripheral (BALF) or central (bronchial wash) airways.

Nitrogen dioxide level need to be taken into account when comparing the subway and road tunnel environments, as it may be a marker for air pollution. Nitrogen dioxide was not present to any greater extent in the subway environment. The World Health Organization (WHO) states that lung function and inflammation in healthy humans are rarely influenced by short-term exposure to nitrogen dioxide at levels such as those seen in the subway environment $\left(<1 \mathrm{ppm}=1.880 \mu \mathrm{g} \cdot \mathrm{m}^{-3}\right)$ [19].

PM10 from the subway station showed a high metal content, mainly iron, which derives from wear of the wheels, rails and brakes. Another important difference between the two environments is that the number concentration of UF particles was 10 times higher in the road tunnel. There were also high levels of nitrogen monoxide and dioxide in the road tunnel, mainly from exhaust fumes, which are not present to a major extent in the subway. These differences in exposure might perhaps explain the discrepancies in inflammatory changes between the two studies.

Epidemiological studies show that the risk of cancer, respiratory and cardiovascular disease can be related to exposure to combustion products $[1,2]$. The associations are difficult to explain and the mechanisms are not fully understood, but particles generated by combustion, for example, are suspected to influence the heart by inflammation that leads to increased coagulation [20]. However, subway drivers do not show any increased relative risk for myocardial infarction [21]. The exposure levels for the subway drivers have not been very high and the cohorts under study have been limited in numbers.

In two in vitro studies, cytokine release (IL-6, IL- 8 and TNF- $\alpha$ ) from human macrophages was stimulated by particles derived from a subway station and a busy urban street. Street particles were the most potent stimulators [22, 23]. Similar results regarding cytokine release were shown in an in vitro animal study using a murine macrophage-like cell line [18]. Induction of lipid peroxidation, arachidonic acid release and formation of reactive oxygen species were, however, stronger for subway particles than for urban street particles. In an in vivo study C57Bl/6 mice were exposed to different types of particles $(100 \mu \mathrm{g})$, such as subway PM_10 particles and diesel exhaust particles, by intratracheal administration. Signs of inflammatory response were observed in BALF $8 \mathrm{~h}$ after exposure with an increased number of neutrophils (subway and diesel exhaust particles) as well as inflammatory mediators TNF- $\alpha$ and macrophage inflammatory protein (subway) [24]. The discrepancies with our results could be explained by the exposure methods used, intratracheal administration versus normal inhalation of larger particles, which target different lung compartments.

To our knowledge, only one previous study has investigated the acute health effects in humans caused by exposure in the subway environment. It showed that the inflammatory response, measured as plasma concentrations of PAI-1, IL-6 and fibrinogen, had a tendency to be higher for subway platform workers than for nonsmoking healthy train drivers and subway ticket sellers [16]. In our present study, the plasma levels of fibrinogen also increased after subway exposure. No such effect was seen in our road tunnel study [9]. The increase was, however, very modest and within the normal range. The findings are supported by a study in London of $>6,000$ office workers which showed that increased levels of urban PM10 correlated with increased levels of plasma fibrinogen [25]. A prospective longitudinal study of $>1,000$ survivors of myocardial infarction showed similar results, with a correlation between particle number concentration and blood IL-6 levels [26]. In our present study, we did not detect any significant release of inflammatory cytokines after the subway exposure.

Blood CD4 cells showed a small but statistically significantly increased expression of activation markers CD69 and HLA-DR after the subway exposure, and similar results applied to CD8 cells regarding the activation marker CD69. Such small increases in the levels of CD69 and HLA-DR in blood cells might not have been detected in the BALF compartment because they already express high levels of activation markers or because the time point of analysis might be inadequate.

Regulatory T-cells are important regulators of immune tolerance. In order to delineate T-cells with regulatory functions, we analysed the CD4 cell expression of FOXP3 alone or in combination with $\mathrm{CD} 25^{\text {bright }}$, which were the markers available at the time. We found an upregulation in the peripheral blood but not in the BALF after subway exposure. It would have been interesting to analyse the expression of CD127 as an additional regulatory T-cell marker. However, we were unable to add this marker at the time of our study [27]. Subway particles may generate oxidative stress [22] but we cannot exclude the possibility that psychological stress itself may affect our results. Psychological stress may increase the proportion of regulatory T-cells, which was shown in a previous study where a group of students were followed during an examination in a control situation [28]. No differences were observed in the NK and NK T-cell populations in blood or BALF after subway exposure, while in our previous road tunnel study both decreased in BALF after exposure [9].

The relatively young study population (only four volunteers were aged $>30 \mathrm{yrs}$ ) could perhaps have influenced the results. However, we have previously been able to demonstrate a cellular response after road tunnel exposure in a study population with a similar age and sex distribution to the present one. Every subject served as their own control, which also strengthens the findings of this study. The choice of 
sampling time could also have affected the outcome, but we found positive results in the road tunnel study using the same sampling time point (14 $\mathrm{h}$ post-exposure).

The results from our study show that a 2-h exposure of healthy individuals to a subway environment leads to an upregulation of T-cells with a phenotype compatible with T-regulatory functions and a limited increase in blood fibrinogen levels. Although no cellular response or increased levels of inflammatory cytokines were detected in either blood or BALF, the findings indicate a minor biological response due to the subway environment. The function role of the T-regulatory cells is not entirely clear. It is still too early to conclude whether this imposes a real health risk to the population. Further studies are needed to evaluate these effects.

It is clear that, even if exposure environments are similar with regard to mass concentrations like PM2.5 and PM10, a risk assessment cannot be based solely on this exposure information since the particle characteristics can differ substantially in size and composition. More complex measurements are needed of particles, including number concentration levels of UF particles as well as knowledge of the source of the particles.

\section{SUPPORT STATEMENT}

This study was sponsored by the Swedish Rail Administration (Banverket) and supported by the Mats Kleberg Foundation and Karolinska Institutet (Stockholm, Sweden).

\section{STATEMENT OF INTEREST}

A statement of interest for this study can be found at www.erj. ersjournals.com $/ \mathrm{misc} /$ statements.dtl

\section{ACKNOWLEDGEMENTS}

The authors wish to thank E. Bernmark (Dept of Public Health Sciences, Karolinska Institutet, Stockholm, Sweden), H. Blomqvist, M. Dahl, G. De Forest, B. Dahlberg (all Dept of Medicine, Karolinska Institutet), S. Gustavsson (Institute of Environmental Medicine, Karolinska Institutet) and L. Broman (Dept of Clinical Sciences, Karolinska Institutet), for their excellent technical assistance in this project. They also thank the Swedish Rail Administration (Banverket) who sponsored the study. Support from the Mats Kleberg Foundation and Karolinska Institutet are also acknowledged.

\section{APPENDIX}

TABLE 3 Three antibody combination panels for determination of lymphocyte subsets in bronchoalveolar lavage fluid and blood

$\begin{array}{lcc}\text { CD3 } & \text { CD3 } & \text { CD3 } \\ \text { CD4 } & \text { CD4 } & \text { CD4 } \\ \text { CD8 } & \text { CD8 } & \text { CD8 } \\ \text { CD45 } & \text { CD69 } & \text { CD25 } \\ \text { CD56 }{ }^{\text {pos }} \text { CD16 }{ }^{\text {pos }} & \text { HLA-DR } & \text { CD69 } \\ \text { CD19 } & & \text { FOXP3 }\end{array}$

All monoclonal antibodies used for phenotypic characterisation of T-cells and T-cell activation are from BD Bioscience (San Jose, CA, USA), apart from Forkhead box P3 (FOXP3), which was purchased from eBioscience (San Jose, CA, USA). TBNK: T-, B- and natural killer (NK)-cells; CD3: T-cell marker; CD4: T-helper/inducer; CD8: Tcytotoxic/suppressor; CD25: anti-interleukin receptor activation; CD45: white blood cells (leukocytes); CD69: early activation; CD56 ${ }^{\text {pos }}$ CD16 ${ }^{\text {pos: }}$ NK cells or NK T-cells; CD19: B-cells; human leukocyte antigen (HLA)-DR: major histocompatibility complex II activation; FOXP3: T-regulatory cell, preferentially CD4 ${ }^{\text {pos }}$ CD25 ${ }^{\text {bright }}$.

TABLE 4 Comparisons between lung function, cellular response in blood, bronchoalveolar lavage (BAL) fluid and bronchial wash from control and subway exposure

\begin{tabular}{|c|c|c|}
\hline Outcome parameter & Control exposure & Subway exposure \\
\hline VC \% pred & $109 \pm 14$ & $111 \pm 13$ \\
\hline FEV $1 \%$ pred & $105 \pm 12$ & $105 \pm 14$ \\
\hline Exhaled NO ppb & $18 \pm 8$ & $17 \pm 9$ \\
\hline PEF total after exposure $L \cdot \min ^{-1}$ & $537 \pm 138$ & $522 \pm 113$ \\
\hline Leukocytes & $5.7(5.1-6.7)$ & $5.6(5.2-6.5)$ \\
\hline Neutrophils & $2.8(2.6-4.0)$ & $2.9(2.5-3.6)$ \\
\hline Eosinophils & $0.1(0.1-0.2)$ & $0.1(0.1-0.2)$ \\
\hline Basophils & $0.1(0.1-0.1)$ & $0.1(0.1-0.1)$ \\
\hline Lymphocytes & $2.4(2.0-2.6)$ & $2.4(1.9-2.7)$ \\
\hline
\end{tabular}




\section{TABLE 4 Continued}

\section{Blood differential \% \\ Neutrophils \\ Eosinophils \\ Basophils \\ Lymphocytes \\ Monocytes}

\section{BAL findings}

Recovery \%

Viability \%

Total number of cells $\times 10^{6}$

Total cell concentration $\times 10^{6} \cdot \mathrm{L}^{-1}$

Number of mast cells ${ }^{\#}$

\section{Cell concentrations in BAL fluid $\times 10^{6} \cdot \mathrm{L}^{-1}$}

Macrophages

Lymphocytes

Neutrophils

Eosinophils

Basophils

\section{Cell differential in BAL fluid \%}

\section{Macrophages}

Lymphocytes

Neutrophils

Eosinophils

Basophils

\section{BW findings}

Recovery \%

Viability \%

Total number of cells $\times 10^{6}$

Total cell concentration $\times 10^{6} \cdot \mathrm{L}^{-1}$

Number of mast cells ${ }^{\#}$

\section{Cell concentrations in BW fluid $\times 10^{6} \cdot \mathrm{L}^{-1}$}

Macrophages

Lymphocytes

Neutrophils

Eosinophils

Basophils

\section{Cell differential in BW fluid \%}

Macrophages

Lymphocytes

Neutrophils

Eosinophils

Basophils

Cytokine concentrations in BAL fluid pg $\cdot \mathrm{L}^{-1}$

IL-1 $\beta$
IL-6
IL-8
IL-10
IL-12p70
TNF- $\alpha$

PAl-1 in blood kilounits $\mathrm{L}^{-1}$

PAI-1

$$
\begin{gathered}
50.8(46.5-54.8) \\
2.0(1.8-3.0) \\
1.8(1.5-2.0) \\
40.2(35.1-43.9) \\
5.9(5.3-7.0) \\
74.0(71.2-78.2) \\
95.3(91.3-98.1) \\
14.3(12.3-17.8) \\
79.5(67.8-98.9) \\
1.5(0.0-5.0) \\
\\
66.8(56.7-84.9) \\
8.8(5.6-17.2) \\
1.4(0.9-1.9) \\
0.1(0.0-0.4) \\
0.0(0.0-0.0)
\end{gathered}
$$

\section{$85.9(80.4-89.4)$ \\ $11.3(8.3-17.9)$ \\ $1.9(1.2-2.2)$ \\ $0.2(0.0-0.4)$ \\ $0.0(0.0-0.0)$}

\section{0 (37.0-50.0) \\ $82.0(67.0-94.0)$ \\ $0.4(0.2-0.8)$ \\ $52.5(30.0-99.1)$ \\ $2.0(0.0-4.5)$ \\ $51.9(51.7-52.2)$ \\ $2.2(2.1-2.3)$ \\ 14.7 (3.3-26.0) \\ $0.1(0.1-1.2)$ \\ $0.0(0.0-0.0)$}

\section{$64.6(56.8-73.0)$ \\ $5.6(3.5-8.2)$ \\ $28.0(18.2-34.5)$ \\ $0.2(0.0-0.5)$ \\ $0.0(0.0-0.0)$}

\section{8 (57.8-165.9)}

394.9 (263.2-963.0)

8569.5 (4646.8-19802.3)

$$
\begin{gathered}
15.2(5.5-21.2) \\
14.8(10.6-24.0) \\
8.9(1.0-58.6)
\end{gathered}
$$

$$
\begin{gathered}
51.7(45.8-54.9) \\
2.0(1.8-3.4) \\
1.8(1.6-1.9) \\
40.5(35.9-45.2) \\
6.1(5.0-7.1) \\
70.7(64.5-75.4) \\
95.5(94.3-97.7) \\
12.7(10.1-17.0) \\
75.1(59.2-96.2) \\
1.5(1.0-4.0) \\
\\
60.4(50.1-86.1) \\
8.2(6.0-13.5) \\
1.7(1.1-2.4) \\
0.1(0.0-0.5) \\
0.0(0.0-0.0)
\end{gathered}
$$

85.3 (81.9-88.3)

$11.4(8.2-15.9)$

$2.2(1.4-3.0)$

$0.2(0.0-0.6)$

$0.0(0.0-0.0)$

$40.0(35.0-50.0)$

$75.0(58.0-86.0)$

$0.7(0.3-1.0)$

$85.0(36.0-133.0)$

$2.0(0.0-3.0)$

$$
\begin{gathered}
57.8(57.8-57.8) \\
6.9(6.9-6.9) \\
5.2(5.2-5.2) \\
0.1(0.1-0.1) \\
0.0(0.0-0.0)
\end{gathered}
$$

$$
\begin{gathered}
55.8(41.3-76.8) \\
5.7(3.6-10.0) \\
38.3(11.4-54.0) \\
0.3(0.0-0.7) \\
0.0(0.0-0.0)
\end{gathered}
$$

64.9 (53.1-139.8)

391.9 (272.0-686.4)

4901.0 (3696.0-14260.0)

$9.6(6.3-17.3)$

$13.7(8.0-22.1)$

$8.2(0.0-49.0)$

Data are presented as mean \pm SD or median (interquartile ranges). Peak expiratory flow (PEF) quotient after/before exposure is presented as the mean of all PEF values after exposure divided by measurement performed before exposure at control and subway exposure, respectively. VC: vital capacity; \% pred: \% predicted; FVC: forced vital capacity; FEV1: forced expiratory volume in $1 \mathrm{~s}$; NO: nitric oxide; BW: bronchial wash; IL: interleukin; TNF: tumour necrosis factor; PAI-1: plasminogen activator inhibitor-1. \# : enlarged 16 times/10 visual fields. 


\section{REFERENCES}

1 Boffetta P, Jourenkova N, Gustavsson P. Cancer risk from occupational and environmental exposure to polycyclic aromatic hydrocarbons. Cancer Causes Control 1997; 8: 444-472.

2 Pope CA 3rd, Burnett RT, Thun MJ, et al. Lung cancer, cardiopulmonary mortality, and long-term exposure to fine particulate air pollution. JAMA 2002; 287: 1132-1141.

3 Ljungman PL, Berglind N, Holmgren C, et al. Rapid effects of air pollution on ventricular arrhythmias. Eur Heart J 2008; 29: 28942901.

4 Monteiller C, Tran L, MacNee W, et al. The pro-inflammatory effects of low-toxicity low-solubility particles, nanoparticles and fine particles, on epithelial cells in vitro: the role of surface area. Occup Environ Med 2007; 64: 609-615.

5 Renwick LC, Brown D, Clouter A, et al. Increased inflammation and altered macrophage chemotactic responses caused by two ultrafine particle types. Occup Environ Med 2004; 61: 442-447.

6 Becker S, Soukup JM, Sioutas C, et al. Response of human alveolar macrophages to ultrafine, fine, and coarse urban air pollution particles. Exp Lung Res 2003; 29: 29-44.

7 Li XY, Gilmour PS, Donaldson K, et al. In vivo and in vitro proinflammatory effects of particulate air pollution (PM10). Environ Health Perspect 1997; 105: Suppl. 5, 1279-1283.

8 Johansson C, Johansson P-Å. Particulate matter in the underground of Stockholm. Atmos Environ 2003; 37: 3-9.

9 Larsson BM, Sehlstedt M, Grunewald J, et al. Road tunnel air pollution induces bronchoalveolar inflammation in healthy subjects. Eur Respir J 2007; 29: 699-705.

10 Adams HS, Nieuwenhuijsen MJ, Colvile RN, et al. Fine particle (PM2.5) personal exposure levels in transport microenvironments, London, UK. Sci Total Environ 2001; 279: 29-44.

11 Seaton A, Cherrie J, Dennekamp $\mathrm{M}$, et al. The London Underground: dust and hazards to health. Occup Environ Med 2005; 62: 355-362.

12 Ripanucci G, Grana M, Vicentini L, et al. Dust in the underground railway tunnels of an Italian town. J Occup Environ Hyg 2006; 3: 16-25.

13 Chillrud SN, Grass D, Ross JM, et al. Steel dust in the New York City subway system as a source of manganese, chromium, and iron exposures for transit workers. J Urban Health 2005; 82: 33-42.

14 Kim KY, Kim YS, Roh YM, et al. Spatial distribution of particulate matter (PM10 and PM2.5) in Seoul Metropolitan Subway stations. J Hazard Mater 2008; 154: 440-443.

15 Plato N, Bigert C, Larsson B-M, et al. Air pollution in the underground of Stockholm: exposure to particles and nitrogen dioxide among subway staff (in Swedish). Internal report 2006:2. Stockholm, Department of Occupational and Environmental Health, Stockholm Center for Public Health, 2006.
16 Bigert $\mathrm{C}$, Alderling $\mathrm{M}$, Svartengren $\mathrm{M}$, et al. Blood markers of inflammation and coagulation and exposure to airborne particles in employees in the Stockholm underground. Occup Environ Med 2008; 65: 655-658.

17 Eklund A, Blaschke E. Relationship between changed alveolarcapillary permeability and angiotensin converting enzyme activity in serum in sarcoidosis. Thorax 1986; 41: 629-634.

18 Lindbom J, Gustafsson M, Blomqvist G, et al. Wear particles generated from studded tires and pavement induces inflammatory reactions in mouse macrophage cells. Chem Res Toxicol 2007; 20: 937-946.

19 World Health Organization (WHO). Air quality guidelines. Global update 2005. Particulate matter, ozone, nitrogen dioxide and sulphur dioxide. WHO Regional Office for Europe, 2006. www. euro.who.int/_data/assests/pdf_file/0005/78638/E90038.pdf

20 Pope CA 3rd, Burnett RT, Thurston GD, et al. Cardiovascular mortality and long-term exposure to particulate air pollution: epidemiological evidence of general pathophysiological pathways of disease. Circulation 2004; 109: 71-77.

21 Bigert C, Klerdal K, Hammar N, et al. Myocardial infarction in Swedish subway drivers. Scand J Work Environ Health 2007; 33: 267-271.

22 Karlsson H, Ljungman A, Lindbom J, et al. Comparison of genotoxic and inflammatory effects of particles generated by wood combustion, a road simulator and collected from street and subway. Toxical Lett 2006; 65: 203-211.

23 Lindbom J, Gustafsson M, Blomqvist G, et al. Exposure to wear particles generated from studded tires and pavement induces inflammatory cytokine release from human macrophages. Chem Res Toxicol 2006; 19: 521-530.

24 Bachoual R, Boczkowski J, Goven D, et al. Biological effects of particles from the Paris subway system. Chem Res Toxicol 2007; 20: 1426-1433.

25 Pekkanen J, Brunner EJ, Anderson HR, et al. Daily concentrations of air pollution and plasma fibrinogen in London. Occup Environ Med 2000; 57: 818-822.

26 Ruckerl R, Greven S, Ljungman P, et al. Air pollution and inflammation (interleukin-6, C-reactive protein, fibrinogen) in myocardial infarction survivors. Environ Health Perspect 2007; 115: 1072-1080.

27 Liu W, Putnam AL, Xu-Yu Z, et al. CD127 expression inversely correlates with FoxP3 and suppressive function of human CD4+ T reg cells. J Exp Med 2006; 203: 1701-1711.

28 Höglund $\mathrm{CO}$, Axen J, Kemi C, et al. Changes in immune regulation in response to examination stress in atopic and healthy individuals. Clin Exp Allergy 2006; 36: 982-992. 